\title{
Isolation, identification and characterization of Paenibacillus polymyxa CR1 with potentials for biopesticide, biofertilization, biomass degradation and biofuel production
}

Brian Weselowski ${ }^{1}$, Naeem Nathoo ${ }^{1,2}$, Alexander William Eastman ${ }^{1,3}$, Jacqueline MacDonald ${ }^{3}$ and Ze-Chun Yuan ${ }^{1,3^{*}}$

\begin{abstract}
Background: Paenibacillus polymyxa is a plant-growth promoting rhizobacterium that could be exploited as an environmentally friendlier alternative to chemical fertilizers and pesticides. Various strains have been isolated that can benefit agriculture through antimicrobial activity, nitrogen fixation, phosphate solubilization, plant hormone production, or lignocellulose degradation. However, no single strain has yet been identified in which all of these advantageous traits have been confirmed.

Results: P. polymyxa CR1 was isolated from degrading corn roots from southern Ontario, Canada. It was shown to possess in vitro antagonistic activities against the common plant pathogens Phytophthora sojae P6497 (oomycete), Rhizoctonia solani 1809 (basidiomycete fungus), Cylindrocarpon destructans 2062 (ascomycete fungus), Pseudomonas syringae DC3000 (bacterium), and Xanthomonas campestris 93-1 (bacterium), as well as Bacillus cereus (bacterium), an agent of food-borne illness. P. polymyxa CR1 enhanced growth of maize, potato, cucumber, Arabidopsis, and tomato plants; utilized atmospheric nitrogen and insoluble phosphorus; produced the phytohormone indole-3-acetic acid (IAA); and degraded and utilized the major components of lignocellulose (lignin, cellulose, and hemicellulose).
\end{abstract}

Conclusions: P. polymyxa CR1 has multiple beneficial traits that are relevant to sustainable agriculture and the bio-economy. This strain could be developed for field application in order to control pathogens, promote plant growth, and degrade crop residues after harvest.

Keywords: Paenibacillus polymyxa, plant growth promotion, PGPR, antagonism, biocontrol, biopesticide, biological nitrogen fixation, diazotroph, biofertilizer, biomass degradation

\section{Background}

Plant-growth promoting rhizobacteria can be exploited in agriculture as an environmentally friendlier alternative to chemical fertilizers and pesticides, which often pollute the environment [1-3]. Such bacteria naturally inhabit plant roots and the surrounding soil (rhizosphere), where they utilize plant-derived nutrients while benefiting the plant

\footnotetext{
*Correspondence: zyuan27@uwo.ca; yuanz@agr.gc.ca

'London Research and Development Centre, Agriculture \& Agri-Food Canada, 1391 Sandford Street, London, ON N5V 4T3, Canada

${ }^{3}$ Department of Microbiology \& Immunology, Dental Science Building Rm.

3014, University of Western Ontario, London, ON N6A 5C1, Canada

Full list of author information is available at the end of the article
}

through a variety of direct or indirect mechanisms [4]. Direct mechanisms can include fixing atmospheric nitrogen, solubilizing mineral phosphates [5-7], synthesizing phytohormones such as indole-3-acetic acid (IAA) that are readily taken up by plant roots, and enhancing plant tolerance to abiotic stress through lowering host ethylene levels by 1-aminocyclopropane-1-carboxylate (ACC) deaminase activity [8-11]. Indirect mechanisms of plantgrowth promotion include inhibition of phytopathogens, induction of plant systemic resistance against pathogens, stabilization of soil aggregates, and maintenance of soil nutrients and structure [12]. 
The plant-growth promoting rhizobacterium Paenibacillus polymyxa has attracted considerable attention because of the demonstrated abilities of its various strains to encourage crop growth via one or more mechanisms, as well as produce lignocellulose-modifying enzymes [13] which could contribute to in situ degradation of crop residues that are often burnt, affecting air quality and public health [14]. Among the most studied strains, P. polymyxa SQR-21 and E681 are known primarily for their ability to suppress plant disease $[15,16]$, while $P$. polymyxa P2b-2R promotes plant growth by fixing nitrogen $[17,18]$.

Comparative genomic analyses of multiple strains reveal that $P$. polymyxa gene clusters encoding antimicrobial peptides are structurally and functionally diverse, perhaps having been acquired by horizontal transfer from other species $[19,20]$. Genes that encode enzymes involved in lignocellulose degradation are also somewhat variable among strains [20], and while all studied strains have putative genes for phosphate solubilization and production of the plant hormone IAA, only a few contain the nif gene cluster required for nitrogen fixation $[19,20]$. To our knowledge, no single $P$. polymyxa strain has yet been described in which all five of these advantageous traits have been confirmed in vivo (antimicrobial, lignocellulose-degrading, phosphate solubilizing, IAA-producing, nitrogen fixing).

While the recently sequenced genome of $P$. polymyxa CR1 suggests that this strain has all of the mentioned traits [20], studies have not yet been published confirming these abilities. The current work therefore describes the isolation of $P$. polymyxa CR1 from degrading corn roots, its in vitro antagonistic activities against common plant pathogens, and its ability to promote growth of important agricultural crops. We further confirm the capability of this strain to fix atmospheric nitrogen fixation, utilize inorganic phosphate, produce the plant hormone IAA, and degrade the major components of lignocellulose.

\section{Results and discussion Species identification}

P. polymyxa strain CR1 was isolated from degrading corn roots and named based on phylogenetic analysis and phenotypic characterization, where CR1 is for "corn rhizobacterium 1". P. polyxyxa CR1 formed hard, sticky colonies when grown on 1/5 NPT agar, exhibiting a translucent to white-yellow color. Phylogenetic analysis was based on the 16S rRNA gene sequenced in this work and deposited in Genbank (accession no. KF620436.1, the isolate's full genome has since been sequenced [20-22]). The 16S rRNA gene was aligned against the NCBI nucleotide database using Blastn, showing $99 \%$ identity to sequences from $P$. polymyxa strains E681 (CP000154.1), SC2, and M1. Identity to sequences from other Paenibacillus species was lower, e.g. $94 \%$ identity to Paenibacillus validus (AB073203), $93 \%$ to Paenibacillus koreensis (AF130254), and $93 \%$ to Paenibacillus larvae (X60619). These 16S rRNA gene sequences, along with those from other relevant bacteria, were used to construct a phylogenetic tree (Fig. 1).

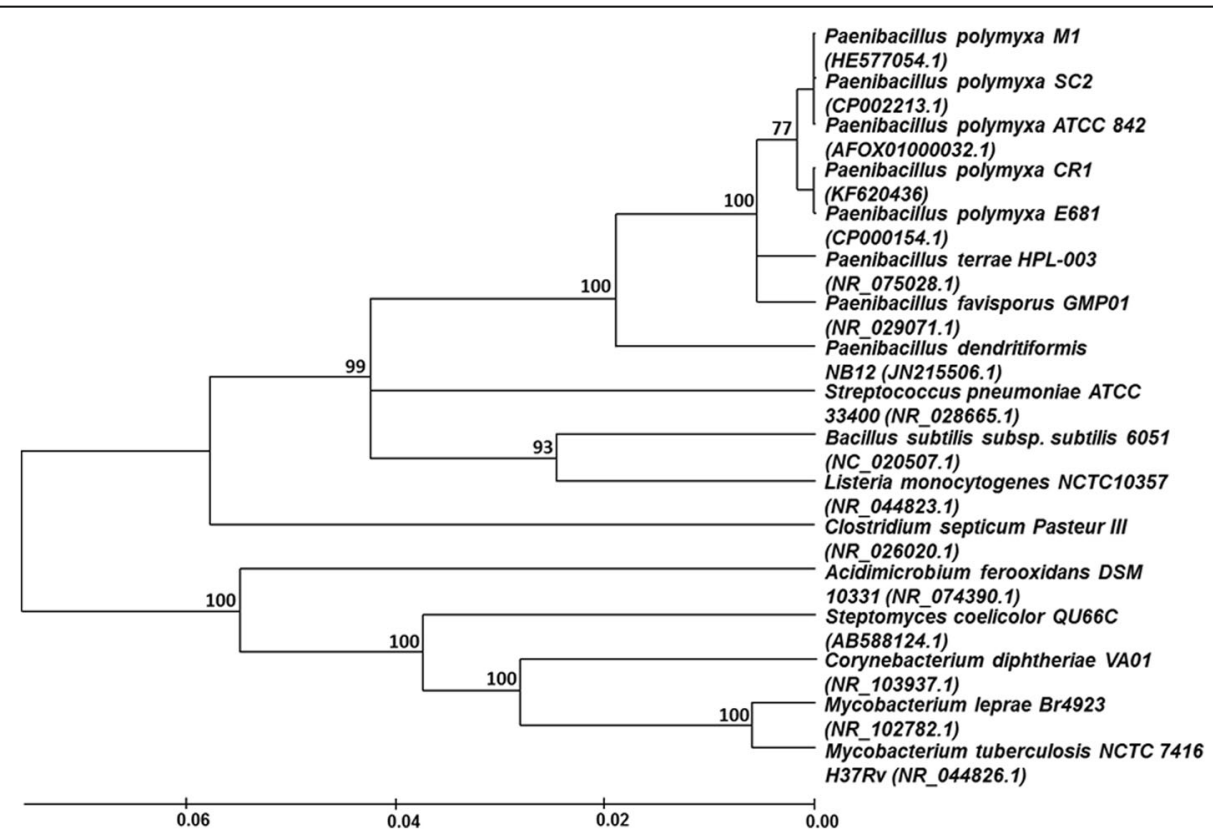

Fig. 1 Phylogenetic tree of bacterial 16S rRNA sequences revealing P. polymyxa evolutionary divergence. Manually refined 16S rRNA sequences were aligned using MEGA 6 and the tree was constructed using the neighbor-joining method (approximately 1400 bp length fragments after refinement). Bootstrap values are indicated at tree branching points. P. polymyxa strains CR1 and E681, in reference to all P. polymyxa strains, are considered to be monophyletic, while remaining closely related to M1, SC2 and ATCC 842 strains 


\section{Antagonistic activity against microbial pathogens}

A total of 1293 bacterial colonies were isolated from degrading corn roots and further screened for antagonism against pathogenic microorganisms using a dual-culture technique. Of the tested isolates, 12 demonstrated growth antagonism towards at least one phytopathogen. $P$. polyxyxa CR1, referred to as "antifungal B" prior to species identification, grew rapidly compared to the other eleven isolates (data not shown) and exhibited antagonism toward six tested pathogens (Fig. 2): Phytophthora sojae P6497 (an oomycete causing stem and root rot of soybean, Fig. 2a), Rhizoctonia solani 1809 (a basidiomycete fungus pathogen of soybean, Fig. 2b), Cylindrocarpon destructans 2062 (an ascomycete fungus causing root rot of ginseng, Fig. 2c); and the bacteria Pseudomonas syringae DC3000 (bacterial speck, Fig. 2d), Xanthomonas campestris 93-1 (bacterial blight, cankers and leaf spots, Fig. 2e), and Bacillus cereus BcMOR28 (causes human foodborne illness, Fig. 2f). It did not affect growth of Agrobacterium tumefaciens, the causal agent of crown gall disease (data not shown). These pathogens were tested because of their phylogenetic diversity, relevance, and availability in our lab. The observations suggest that $P$. polyxyxa CR1 produces considerable amounts of anti-microbial substances that antagonize the growth of a broad range of microbial pathogens.

Various strains of $P$. polymyxa have previously been found to antagonize microorganisms related to some of the ones tested here, including Phytophthora species [23, 24], $R$. solani $[25,26], P$. syringae [27], and $X$. campestris [28]. In some cases, responsible antimicrobial compounds have been identified: fusaricidin against Phytophthora capsici [29], a $\sim 35 \mathrm{kDa}$ antifungal peptide against $R$. solani $[25,26]$, and gavaserin and saltavalin against $X$. campestris [28]. Notably, not all strains of $P$. polymyxa are antagonistic toward these organisms [24], an observation which is consistent with the diversity among strains in their gene clusters that encode antimicrobial peptides $[19,20]$. The specific antimicrobial compounds produced by $P$. polymyxa CR1 are yet to be identified.

Plant growth promotion (corn, cucumber, tomato, potato and Arabidopsis)

Inoculation of plants with $P$. polymyxa CR1 resulted in increased plant growth relative to controls (Fig. 3). Inoculation of maize lead to a $19 \% \pm 2.3 \%$ SD increase in whole-plant dry weight versus the mock-inoculated control after 8 weeks. In comparison, maize plants inoculated with Gluconacetobacter azotocaptans DS1, an established growth-promoting rhizobacterium [30], lead to a $13 \% \pm 1.2 \%$ SD increase in dry weight versus the control. Inoculation with either bacterium appeared to enhance development of maize roots (Fig. 3a). Potato plantlets inoculated with $P$. polymyxa CR1 were $16 \% \pm 1.7 \%$ SD taller than control plantlets after four weeks (Fig. 3b). Inoculation with $P$. polymyxa CR1 led to a $27 \% \pm 2.1 \%$ $\mathrm{SD}$ increase in cucumber shoot fresh weight after four weeks (Fig. 3c), a $25 \% \pm 3.1 \%$ SD increase in Arabidopsis thaliana Col-0 dry weight after three weeks (Fig. 3d), and a $27 \% \pm 2.3 \%$ SD increase in tomato shoot dry weight after six weeks (Fig. 3e), relative to the controls.
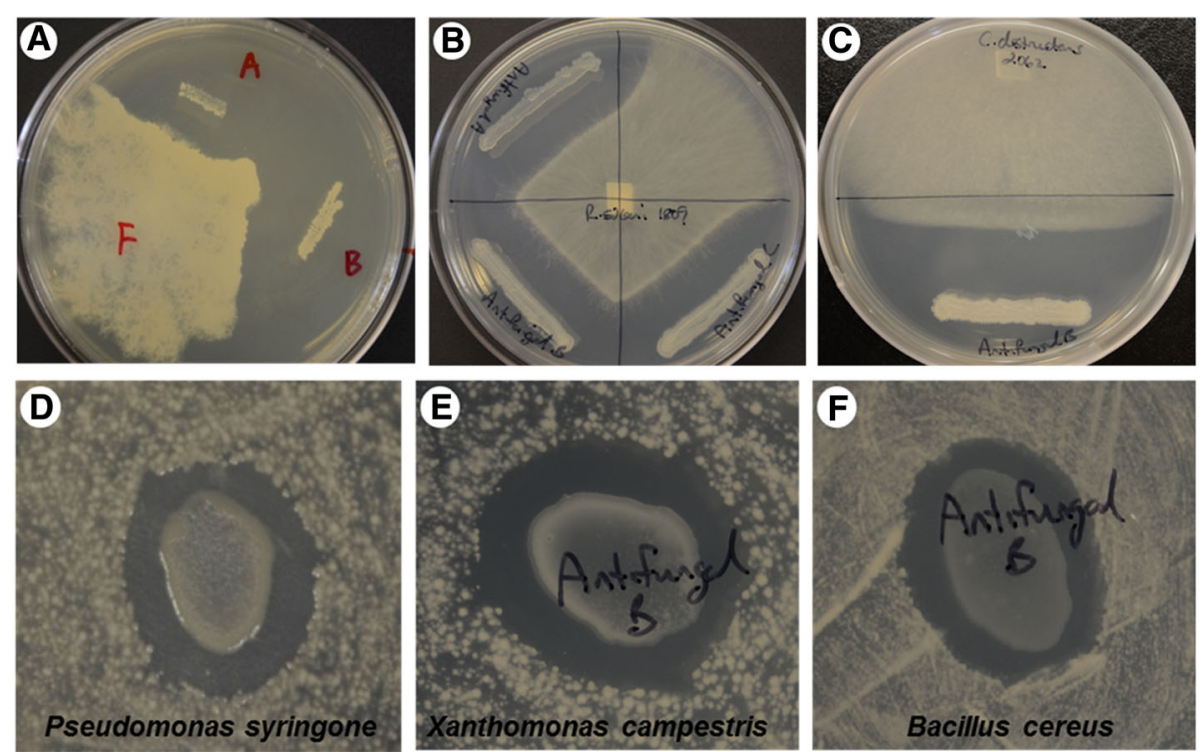

Fig. 2 in vitro antagonistic activity of $P$. polymyxa CR1 against selected pathogens. Dual culture assay tests show zones of inhibition which indicate antagonistic activity against a Phytopthora sojae P6497; b Rhizoctonia solani 1809; c Cyindrocarpon destructans 2062; d Pseudomonas syringone DC3000; e Xanthomonas campestris 93-1; f Bacillus cereus BCMOR28. Tests were done in triplicate, representative plates are shown 

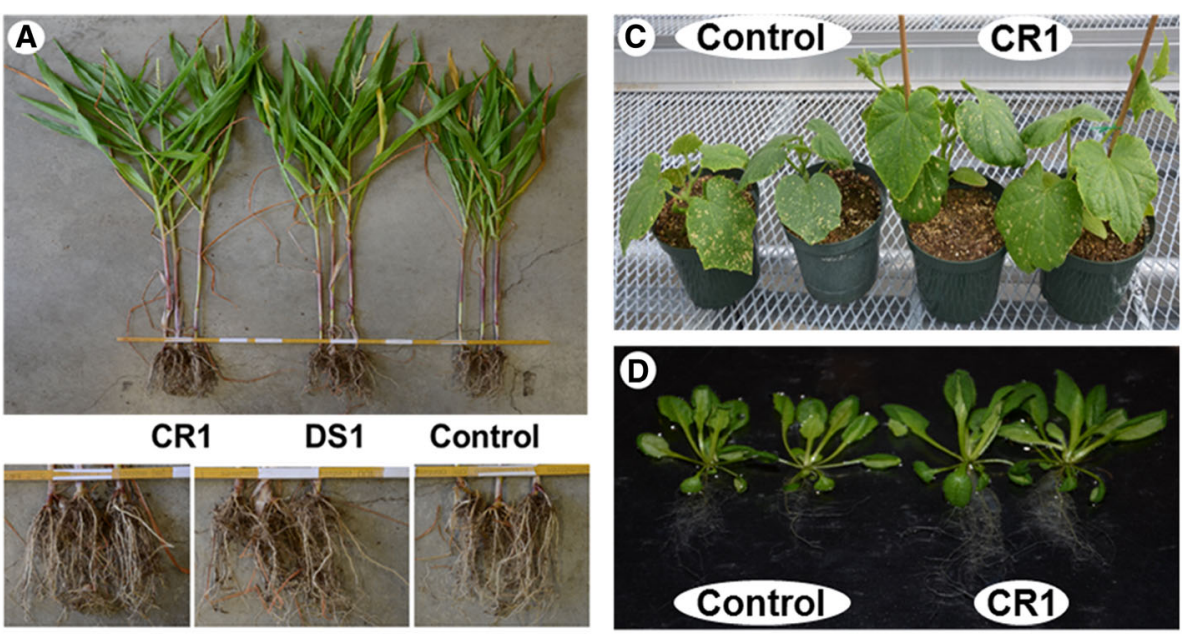

CR1

DS1

Control
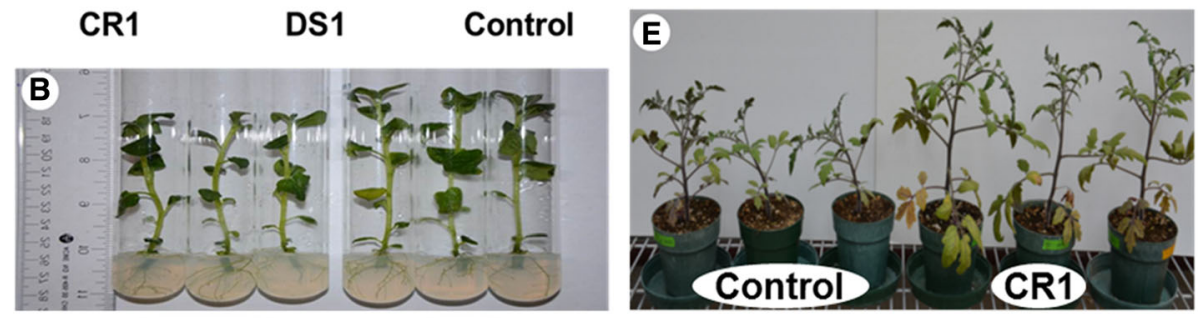

Control

CR1

Fig. 3 Plant growth promotion by P. polymyxa CR1. a Corn plants inoculated by seed soaking with P. polymyxa CR1 in reference to an established growth promoting rhizobacterium, Gluconacetobacter azotocaptans DS1 [30] and control plants. Bottom panel indicates increases density of root formation. b Tissue-culture potato plantlets grown as single-node explants following inoculation with $P$. polymyxa CR1 culture, and control plantlets. c Cucumber plants inoculated at the stem base with P. polymyxa CR1, and control plants. d A. thaliana Col-0 inoculated at the stem base with P. polymyxa CR1, and control plants. e Tomato plants inoculated at the stem base with P. polymyxa CR1, and control plants

Beneficial rhizobacteria can promote plant growth through bacterial nitrogen fixation, IAA hormone production, phosphorus solubilization, or by protecting plants from phytopathogens [4], such as the ones studied above. Our experiments with maize, cucumber, and tomato were conducted in non-sterile soil in a greenhouse. However, the experiments with potato and $A$. thaliana were in soil-free media with agar. While these latter results may not be representative of effects in nature (soil), they do provide evidence of growth promotion due to direct effects of $\mathrm{P}$. polymyxa CR1 inoculation, rather than indirect effects on other rhizosphere microbes. Therefore, factors other than pathogen antagonism, such as IAA production, phosphate solubilization and nitrogen fixation, were expected to have collectively contributed to the observed growth promotion.

\section{Nitrogen fixation}

The vegetative growth of plants (leaves, stems, and roots) is especially dependent on nitrogen fertilizer [1]. The nitrogen-fixing potential of $P$. polymyxa CR1 was therefore assessed by growth on nitrogen-free minimal medium (NFM). Growth of $P$. polymyxa CR1 was visible on the NFM, while Escherichia coli O157:H7, which does not fix nitrogen, grew only on medium supplemented with reactive nitrogen (Fig. 4). These results demonstrate the ability of $P$. polymyxa CR1 to fix nitrogen, which is not surprising given the presence in the $P$. polymyxa CR1 genome of the nif gene cluster [20] that is sufficient to confer nitrogen fixation to Escherichia coli [30].

Nitrogen fertilizers are routinely applied to crops to ensure growth and productivity. However, more than half of synthetic nitrogen fertilizer is not taken up by crops, instead being lost to the environment where it contributes to greenhouse gas production, acid rain, and biodiversity loss in aquatic systems [31]. These detrimental effects could be lessened by inoculating fields with nitrogen-fixing rhizobacteria, allowing for partial replacement of synthetic fertilizers. Accordingly, P. polymyxa CR1 may be able to contribute to the bio-fertilization of a variety of crops.

\section{Phosphorus solubilization}

Like nitrogen, phosphorus is another major essential macronutrient for plant growth, health and productivity [1]. Phosphate based fertilizers (mineral phosphate) are routinely applied to soil in agricultural practice. However, applied phosphate fertilizer is rapidly immobilized through precipitation reaction with highly reactive $\mathrm{Fe} 3+$, aluminum and calcium in soil and consequently becomes unavailable 

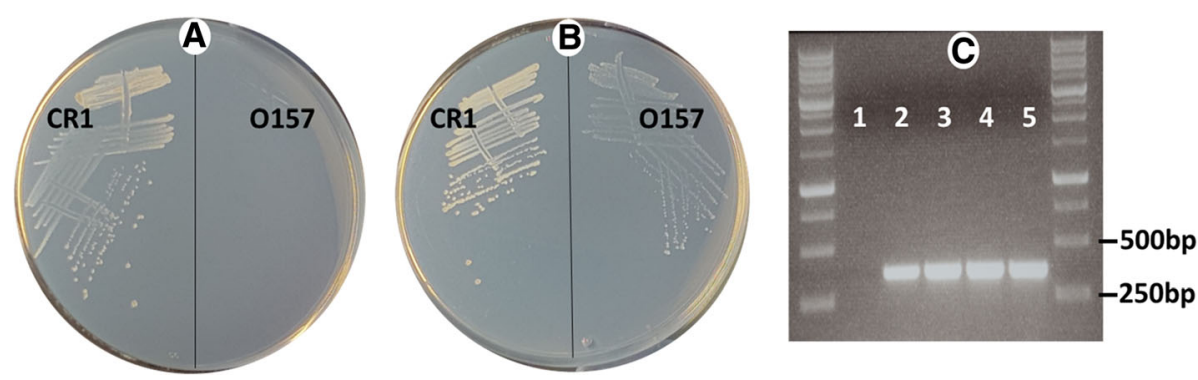

Fig. 4 Nitrogen-fixation by P. polymyxa CR1. P. polymyxa CR1 inoculated on nitrogen free media (NFM) was assessed for growth in reference to non-nitrogen fixing E. coli O157:H7. a NFM medium; b NFM supplemented with $5 \mathrm{mM} \mathrm{NH}_{4} \mathrm{Cl}$; $\mathbf{c}$ The presence of nitrogen fixing genes. Primer pairs PolF and PolR were utilized to amplify $352 \mathrm{bp}$ of the nifH gene from four single colonies of the same P. polymyxa CR1 strain (lanes 2-5), or in a PCR reaction control without DNA (lane 1). Presence of a nif gene cluster was confirmed by DNA sequencing

to plants [7, 32]. Soil erosion also leads to phosphorus loss from soils, which usually accumulates in lakes and rivers causing eutrophication. Microbe-mediated phosphorus solubilization is one of the most important traits relevant to plant growth promotion [7, 32-34].

P. polymyxa CR1 was assessed for its ability to solubilize and utilize inorganic phosphate in the form of tricalcium phosphate $\left[\mathrm{Ca}_{3}\left(\mathrm{PO}_{4}\right)_{2}\right]$. After two weeks of incubation, clear and visible dissolution halos formed around a $P$. polymyxa CR1 colony grown on solid NBRIP medium, in which $\mathrm{Ca}_{3}\left(\mathrm{PO}_{4}\right)_{2}$ is the sole phosphate source (Fig. 5). These dissolution halos indicate the excretion of organic acids or enzymes into the surrounding medium that solubilize $\mathrm{Ca}_{3}\left(\mathrm{PO}_{4}\right)_{2}$. The results therefore suggest an ability to solubilize inorganic phosphate to a form available for plants, although they do not necessarily imply phosphate solubilisation in nature.

\section{Indole 3 acetic acid (IAA) production}

Another way that rhizobacteria can promote plant growth is through synthesis of the phytohormone IAA [35-37], which plays a multifaceted role in plant growth and development. IAA stimulates plant cell elongation and cell division, increasing root size and distribution which leads to greater nutrient absorption from the soil $[38,39]$. Appropriate concentrations of exogenous IAA or IAA agonists also stimulate the growth and development of plant root systems by activating root branching and lateral root development $[10,11]$.

The ability of $P$. polymyxa CR1 to synthesize IAA was determined by reaction of liquid culture with Salkowski's reagent, which detects IAA and its intermediates [9]. The reaction produces a proportionate amount of tric-(indole3 -acetato) iron (III) complex, which is pink in color and can be quantified by measuring absorbance at $535 \mathrm{~nm}$. $P$. polymyxa CR1 produced an average of $62.8 \mu \mathrm{g} / \mathrm{mL} \pm$ $3.4 \mu \mathrm{g} / \mathrm{mL}$ SD of IAA (or its intermediates) when grown with $500 \mathrm{mg} / \mathrm{L}$ L-Tryptophan (the precursor for IAA biosynthesis) in liquid MGN or NPT medium (Table 1).
The difference in IAA production between MGN and NPT medium, with or without tryptophan, was not significant. The genomes of many plant growth promoting bacteria, including $P$. polymyxa [19], encode a transaminase for the oxidative deamination of L-tryptophan to yield indole-3pyruvic acid as an intermediate for IAA production. As expected, significantly more IAA (or its intermediates) was produced in media with tryptophan than without $(p<0.01)$, indicating that $P$. polymyxa CR1 utilizes this tryptophandependent pathway.

\section{Degradation and utilization of lignin, cellulose and hemi-cellulose}

In addition to its growth promoting properties, $P$. polymyxa is known to produce a variety of lignocellulose-modifying

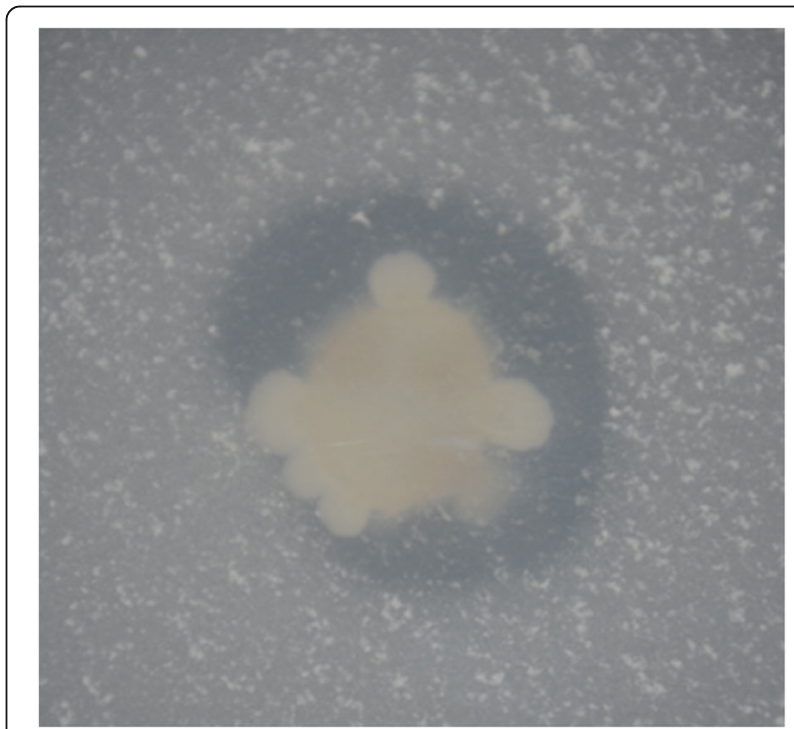

Fig. 5 Inorganic phosphate solubilization by P. polymyxa CR1. CR1 was immobilized on NBRIP plates as described in materials and methods. CR1's capacity to solubilize and use $\mathrm{Ca}_{3}\left(\mathrm{PO}_{4}\right)_{2}$ as a sole source of phosphate was evident as a clearing zone around CR1 inoculum 
Table 1 Indole-3-acetic-acid (IAA) production by P. polymyxa CR1 grown in various media

\begin{tabular}{|c|c|c|c|c|}
\hline & \multicolumn{4}{|c|}{ IAA concentrations $(\mu \mathrm{g} / \mathrm{mL})$ in replicate cultures } \\
\hline & WGN & $W G N+\operatorname{Trp}$ & NPT & NPT + Trp \\
\hline replicate \#1 & 0.9 & 67.1 & 4.4 & 64.2 \\
\hline replicate \#2 & 0.2 & 65.0 & 2.4 & 64.1 \\
\hline replicate \#3 & 0.0 & 57.8 & 1.9 & 58.9 \\
\hline
\end{tabular}

enzymes [13] which can be used in a variety of applications. The ability of $P$. polymyxa CR1 to utilize hemicellulose was confirmed by growth on minimal medium supplemented with xylan (Fig. 6a). P. polymyxa CR1 was grown on minimal medium supplemented with methylene blue, a lignin mimetic, to detect ligninolytic enzyme activity [40]. The oxidation zone (clear halo) around the colony (Fig. 6b) is indicative of lignin metabolism. Cellulose degradation was confirmed by cultivation with carboxymethylcellulose and Congo red, which stains the un-degraded substrate [41], producing a concentric yellow opaque zone of clearing around the colony (Fig. 6c). Our recent genome sequencing confirmed the presence of genes encoding extensive plant cell wall-degrading machinery in the CR1 genome including endoglucanases, cellodextrinases, xylanases, mannanases, arabinofuranosidase, DyP-peroxidase, and laccase [20].

Lignocellulose-degrading bacteria can contribute to nutrient cycling in untilled land by promoting biological decomposition of residues from non-harvested plant parts. Lignocellulose-modifying P. polymyxa CR1, or its isolated enzymes, could also be studied for their potential use in biomass delignification or carbohydrate deconstruction by the biofuels industry. As part of the process for conversion of lignocellulose to fuel or value-added bio-products, it could contribute to a reduced dependency on petrochemicals [42]. To better assess this potential, enzymatic activities (cellulases, xylanases, lignin peroxidases and laccases) will need to be quantitatively assessed under industriallyrelevant conditions, and if justified, optimal fermentation conditions need to be investigated.

\section{Conclusions}

P. polymyxa CR1 possesses several beneficial properties and enhances growth of a variety of important plants. Like most studied strains of $P$. polymyxa, it has the ability to produce the beneficial plant hormone IAA and to solubilize inorganic phosphorous. It is also able to fix atmospheric nitrogen, a trait that is shared by only a select few of the species. Furthermore, while each strain presumably antagonizes a unique set of microorganisms, P. polymyxa CR1 showed antagonistic activity toward key plant pathogens that are phylogenetically diverse. In addition, the strain was shown to utilize and degrade the main components of lignocellulose. To our knowledge, this is the first time that a single $P$. polymyxa strain has demonstrated all of these advantageous traits.

Due to the multiple beneficial effects of $P$. polymyxa CR1, this strain could be developed and commercially formulated, either alone or as part of microbial consortia, for field application in order to control pathogens, promote crop growth, and degrade crop residues after harvest. Further research is needed to establish optimum growth parameters of P. polymyxa CR1, determine factors influencing its competitiveness in soil, and confirm these benefits in field trials.

\section{Methods}

16S rRNA sequencing and phylogenetic tree construction Approximately $1,500 \mathrm{bp}$ of the $16 \mathrm{~S}$ rRNA gene were amplified from $P$. polymyxa CR1 genomic DNA isolated using the Bacterial Genomic DNA Isolation Kit (Norgen Biotek Corp., Thorold, ON, Canada) in accordance with the manufacturer's protocols. The PCR reaction was performed with $2.5 \mu \mathrm{M}$ each primers $8 \mathrm{~F}$ (5'-AGAGTTTGATCCTGGCTCAG-3') and 1492R (5'-GGTTACCTTG TTACGACTT-3') [43], 1.5 U Phusion High-Fidelity DNA Polymerase (Thermo Fisher Scientific Inc., Waltham, MA, USA), $50 \mathrm{ng}$ genomic DNA, $200 \mu \mathrm{M}$ dNTPs, 1X PCR buffer and $2.0 \mathrm{mM} \mathrm{MgCl} 2$ in a total volume of $50 \mu \mathrm{L}$. The cycle parameters were as follows: initial denaturation at $95{ }^{\circ} \mathrm{C}$ for $5 \mathrm{~min}$; 30 cycles of denaturation for $30 \mathrm{~s}$ at $94{ }^{\circ} \mathrm{C}$,

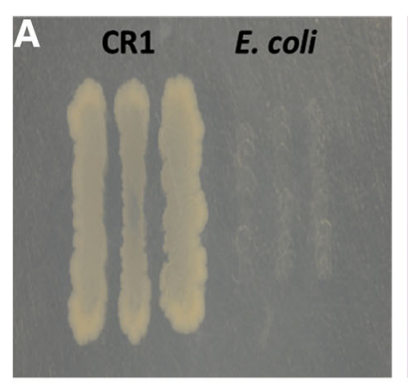

Hemi-cellulose

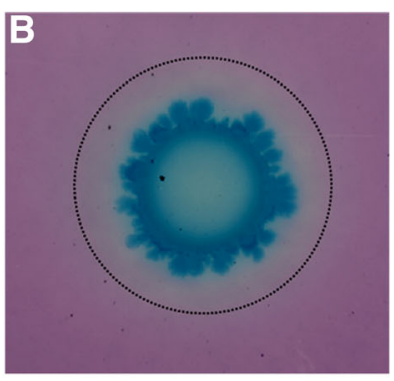

Lignin

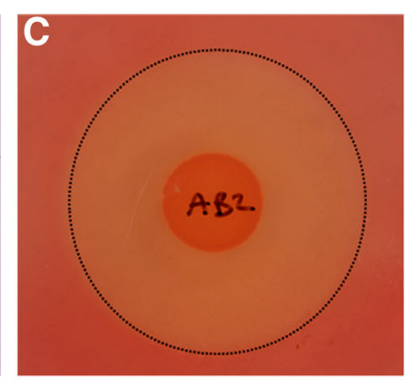

Cellulose

Fig. 6 P. polymyxa CR1 degrades and utilizes semi-cellulose, lignin and cellulose as a sole carbon sources. a) CR1 (left) inoculum on minimal media supplemented with hemi-cellulose compared against E. coli O157:H7 (right). b) CR1 ligninolytic enzyme activity detected by halo surrounding inoculum on minimal medium containing methylene blue. c) Congo red staining for cellulose activity 
annealing for $45 \mathrm{~s}$ at $57^{\circ} \mathrm{C}$, and extension for $60 \mathrm{~s}$ at $72{ }^{\circ} \mathrm{C}$; and a final overall extension for $10 \mathrm{~min}$ at $72{ }^{\circ} \mathrm{C}$. The PCR product was purified using the QIAquick PCR Purification kit (Qiagen, Hilden, Germany) and sequenced with $8 \mathrm{~F}$ and 1492R primers on a 3730 Analyzer (Thermo Fisher Scientific Inc.) at Agriculture and Agri-Food Canada (London, ON, Canada).

The 16S rRNA gene fragment was compared with the NCBI nucleotide database using Blastn. The following bacterial 16S rDNA from taxonomically characterized homologues were collected from the Genbank database on NCBI (http://www.ncbi.nlm.nih.gov/genbank) and used for phylogenetic analysis: Paenibacillus polymyxa M1 (HE577054.1), Paenibacillus polymyxa SC2 (CP0022 13.1), Paenibacillus polymyxa ATCC 842 (AFOX010 00032.1), Paenibacillus polymyxa E681 (CP000154.1), Paenibacillus terrae HPL-003 (NR_075028.1), Paenibacillus favisporus GMP01 (NR_029071.1), Paenibacillus dendritiformis NB12 (JN215506.1), Streptococcus pneumoniae A TCC 33400 (NR_028665.1), Bacillus subtilis subsp. subtilis 6051 (NC_020507.1), Listeria monocytogenes NCTC10357 (NR_044823.1), Clostridium septicum Pasteur III (NR_0 26020.1), Acidimicrobium ferooxidans DSM 10331 (NR_0 74390.1), Steptomyces coelicolor QU66C (AB588124.1), Co rynebacterium diphtheriae VA01 (NR_103937.1), Мycobacterium leprae Br4923 (NR_102782.1), Mycobacterium tuberculosis NCTC 7416 H37Rv (NR_044826.1). Multiple alignments were performed using the CLUSTAL_X program [44] and manually refined. A phylogenetic tree based on a comparison of 1500 bases was constructed using the neighbour-joining [45] and maximum-parsimony [46] methods using the software package MEGA version 4.1 [47]. Evolutionary distances were calculated according to Kimura's two-parameter model [48]. Alignment gaps and ambiguous bases were excluded from the calculation. The topology of the tree was evaluated by bootstraping with 1000 pseudo-replicates. Similarity values were calculated using paup, version 4.0b1 [49].

\section{Isolation of bacteria from degrading corn roots}

Degrading corn roots were collected from the research farm at London Research and Development Centre, Agriculture and Agri-Food Canada, in London, Ontario. Forty grams of degrading corn roots were first rinsed with water followed by 10 thorough washes with autoclaved distilled water to remove adhering soils and microbes that were not tightly associated with roots (no surface sterilization). For the preparation of root bacterial suspensions, root samples were cut into 1-5 mm lengths, suspended in $10 \mathrm{~mL}$ sterile $0.85 \% \mathrm{NaCl}$ and homogenized with a sterile mortar and pestle. Resulting bacterial suspensions were serially diluted with $1 \mathrm{~mL}$ of sterile $0.85 \% \mathrm{NaCl}$ to a final dilution of $10^{-9}$. Subsequently, $100 \mu \mathrm{L}$ aliquots were plated onto $1 / 5 \mathrm{NPT}$ (0.4 g/L nutrient broth, $1 \mathrm{~g} / \mathrm{L}$ potato dextrose, $1.2 \mathrm{~g} / \mathrm{L}$ tryptic soy broth, $2 \mathrm{~g} / \mathrm{L}$ MES hydrate, $15 \mathrm{~g} / \mathrm{L}$ agar, $\mathrm{pH}$ 5.75) and incubated at $28{ }^{\circ} \mathrm{C}$ for $72 \mathrm{~h}$. Individual bacterial colonies were isolated and colony purified twice prior to in vitro antagonism assays.

\section{In vitro antagonism assay}

Dual culture assays tested the antagonistic abilities of isolated bacteria against six microorganism. P. sojae P6497, $R$. solani 1809, and $C$. destructans 2062 were routinely cultured in potato dextrose agar (PDA) at $25^{\circ} \mathrm{C}$, and working stocks were established by transferring a cultured agar plug onto solid $1 / 5 \mathrm{NPT}$ at $25{ }^{\circ} \mathrm{C}$ for 7 days. P. syringae DC3000, X. campestris 93-1, B. cereus BcMOR28, and the isolated bacterial strains were maintained in $1 / 5 \mathrm{NPT}$. Purified isolated bacteria were frozen in $15 \% \mathrm{w} / \mathrm{v}$ glycerol at $-80{ }^{\circ} \mathrm{C}$ for long-term storage.

Anti-microbial activity of selected isolates was assessed under in vitro conditions. Bacterial isolates were cultured on $1 / 5$ NPT agar overnight at $28{ }^{\circ} \mathrm{C}$. Pathogenic bacteria were spread as a lawn on separate 1/5 NPT agar plates and allowed to air-dry in a laminar-flow cabinet. Then, $10 \mu \mathrm{L}$ aliquots of isolated bacterial suspensions $\left(10^{8} \mathrm{CFU} /\right.$ $\mathrm{mL}$ ) pre-grown in 1/5 NPT were evenly spotted on the pathogenic bacterial lawn, with eight different bacterial isolate spots per lawn. The plates were then incubated at $28{ }^{\circ} \mathrm{C}$ for three days, by which time a visible zone of inhibition, which is clear of pathogenic bacterial growth, surrounded the spotted bacterial isolates on some of the plates. A zone of inhibition can form due to diffusion of bacterial metabolites into the agar [50].

For antifungal and anti-oomycete activity, mycelial plugs of $1 \mathrm{~cm}$ diameter were cut from a 6-day-old culture and transferred to the center of a Petri dish containing $1 \mathrm{X}$ NPT medium. After $24 \mathrm{~h}$ incubation at $25{ }^{\circ} \mathrm{C}$, bacterial isolates were streaked in a line approximately 2 to $3 \mathrm{~cm}$ away from the mycelial plug. The plates were then incubated at room temperature (approximately $25^{\circ} \mathrm{C}$ ) for 10 days, until radial growth of the mycelia reached the edge of the plate on the side without bacterial inoculation.

Bacterial isolates that demonstrated consistent antagonistic activity on three replicate plates were single colony purified three times prior to further study or storage.

\section{Plant growth promotion experiment}

P. polymyxa CR1 grown in $1 / 5 \mathrm{NPT}$ and $28^{\circ} \mathrm{C}$ for $24 \mathrm{~h}$ were harvested and diluted in distilled water or nutrient broth for inoculation of plants. Approximate colony forming units per milliliter $(\mathrm{CFU} / \mathrm{mL})$ were determined by optical density and serial dilutions with plate counts.

Tissue-cultured potato plantlets (Solanum tuberosum L. cv. Kennebec) derived from stock plantlets (New Liskeards Agricultural Research Station, New Liskeard, Ontario, Canada) were grown from $1 \mathrm{~cm}$ long single-node explants in $22 \times 150 \mathrm{~mm}$ test tubes containing $10 \mathrm{~mL}$ MS -based 
potato nodal cutting medium (PNCM: $4.4 \mathrm{~g} / \mathrm{L}$ MS basal salt medium (Sigma-Aldrich Corp., St. Louis, MO, USA), $30 \mathrm{~g} / \mathrm{L}$ sucrose, $8 \mathrm{~g} / \mathrm{L}$ noble agar, $\mathrm{pH}$ 6.0). The single-node explants were immersed in $10^{9} \mathrm{CFU} / \mathrm{mL}$ bacterial suspension in distilled water, or distilled water only. Explants were then rinsed in sterile distilled water for $1 \mathrm{~min}$, and air dried on a sterile paper towel prior to planting in PNCM. Tubes were wrapped with 1 in. Micropore tape (3 M, Maplewood, MN, USA) to allow air flow to the plants while preventing fungal spores from entering the tube. Plants were grown in a controlled environmental chamber with an $18 \mathrm{~h} \mathrm{/} 6 \mathrm{~h}$ light / dark cycle with temperatures at $22{ }^{\circ} \mathrm{C}$ (light) and $18^{\circ} \mathrm{C}$ (dark).

Wild-type (WT) Arabidopsis thaliana Col-0 seed (stock no. CS70000) were ordered from the Arabidopsis Biological Resource Center website (https://abrc.osu.e du/order-stocks). Seeds were surface sterilized with $5 \%$ sodium hypochlorite (100\% commercial laundry bleach), rinsed five times with sterile water, and kept at $4{ }^{\circ} \mathrm{C}$ in the absence of light for 2 days to stimulate germination. Seeds were then sown on square Petri dishes $(100 \times$ $100 \times 15 \mathrm{~mm}$ ) with half strength semi-solid Murashige and Skoog medium (MS: half packet/L MS Basal salts, $7.5 \mathrm{~g} / \mathrm{L}$ sucrose, $0.25 \mathrm{~g} / \mathrm{L}$ MES powder, $59 \mathrm{~mL} / \mathrm{L}$ B5 vitamin mix, $3.5 \mathrm{~g} / \mathrm{L}$ agar, $\mathrm{pH}$ of 5.75 using $\mathrm{NaOH}$ ) and placed in a growth room with a $14 \mathrm{~h} / 10 \mathrm{~h}$ light / dark cycle with a total light intensity of $200 \mu \mathrm{mol}$ photons $\mathrm{m}$ $-2 \mathrm{~s}-1$, temperature of $21 \pm 4{ }^{\circ} \mathrm{C}$, and $40 \pm 10 \%$ relative humidity. After two days, the plants were inoculated with $50 \mu \mathrm{L}$ of $10^{9} \mathrm{CFU} / \mathrm{mL}$ bacterial suspension in water, or distilled water only, by streaking below the region of the planted seed.

For tomato, cucumber and corn, seeds were soaked in $10^{8} \mathrm{CFU} / \mathrm{mL}$ bacterial suspension in nutrient broth, or nutrient both only, before sowing into soil and grown in a greenhouse. Soil consisted of equal amounts of Pro-Mix BX (Premier Tech Horticulture, Rivière-du-Loup, QC, Canada) and native soil obtained on-site from the London Research and Development Centre, Agriculture and AgriFood Canada. After 7 days, $300 \mu \mathrm{L}$ of $10^{8} \mathrm{CFU} / \mathrm{mL}$ bacterial suspension in nutrient broth, or nutrient broth only, were inoculated at the base of the plant stems near the substrate interface.

\section{Nitrogen fixation assay}

A single colony of $P$. polymyxa CR1 or Escherichia coli O157:H7 grown on solid 1/5 NPT medium was streaked onto solid nitrogen-deficient malate medium (NFM: $0.1 \mathrm{~g} / \mathrm{L} \mathrm{NaCl}, 0.02 \mathrm{~g} / \mathrm{L} \mathrm{CaCl}_{2}, 0.4 \mathrm{~g} / \mathrm{L} \mathrm{KH}_{2} \mathrm{PO}_{4}, 0.5 \mathrm{~g} / \mathrm{L}$ $\mathrm{K}_{2} \mathrm{HPO}_{4}, 0.2 \mathrm{~g} / \mathrm{L} \mathrm{MgSO}_{4} .7 \mathrm{H}_{2} \mathrm{O}, 0.01 \mathrm{~g} / \mathrm{L} \mathrm{FeCl}_{3}, 0.002 \mathrm{~g} /$ $\mathrm{L} \mathrm{Na}_{2} \mathrm{MoO}_{4} \cdot 2 \mathrm{H}_{2} \mathrm{O}, 5 \mathrm{~g} / \mathrm{L}$ sodium malate, $15 \mathrm{~g} / \mathrm{L}$ agar, $\mathrm{pH}$ 7.2-7.4 using $\mathrm{KOH}$ ) supplemented with $50 \mathrm{mg} / \mathrm{L}$ yeast extract [51]. A resulting single colony was then re- streaked onto NFM to confirm the ability to fix nitrogen [52]. Plates were incubated at $28^{\circ} \mathrm{C}$ for 7 days.

\section{Phosphate solubilization assay}

Phosphate solubilization was evaluated as previously described [53]. Briefly, P. polymyxa CR1 was cultivated on solid NBRIP medium (1\% glucose, $0.5 \% \mathrm{Ca}_{3}\left(\mathrm{PO}_{4}\right)_{2}$, $0.5 \% \mathrm{MgCl}_{2}, 0.01 \%\left(\mathrm{NH}_{4}\right)_{2} \mathrm{SO}_{4}, 0.025 \% \mathrm{MgSO}_{4} .7 \mathrm{H}_{2} \mathrm{O}$, $0.02 \% \mathrm{KCl}, 1.5 \%$ agar), where growth is associated with the capacity to use inorganic phosphate in the form of $\mathrm{Ca}_{3}\left(\mathrm{PO}_{4}\right)_{2}$ as a sole phosphate source. Plates were grown at $28{ }^{\circ} \mathrm{C}$ for 14 days.

\section{Indole 3 acetic acid (IAA) production assay}

Production of IAA and related compounds was based on the colorimetric method previously described, with some modifications $[9,54,10]$. A $20 \mu \mathrm{L}$ aliquot of bacterial culture adjusted to an $\mathrm{OD}_{600}$ of $0.5\left(10^{6}-10^{7} \mathrm{CFU} / \mathrm{mL}\right)$ was used to inoculate $3 \mathrm{~mL}$ of liquid MGN (10 g/L mannitol, $2.32 \mathrm{~g} / \mathrm{L}$ sodium glutamate, $0.5 \mathrm{~g} / \mathrm{L} \mathrm{KH}_{2} \mathrm{PO}_{4}, 0.2 \mathrm{~g} / \mathrm{L}$ $\mathrm{MgSO}_{4}, 0.2 \mathrm{~g} / \mathrm{L} \mathrm{NaCl}, 2 \mu \mathrm{g} / \mathrm{L}$ biotin, $1 \mathrm{~g} / \mathrm{L}$ nutrient broth, $2.5 \mathrm{~g} / \mathrm{L}$ potato dextrose, $3 \mathrm{~g} / \mathrm{L}$ tryptic soy broth, $1 \mathrm{~g} / \mathrm{L} \mathrm{MES}$ hydrate, $\mathrm{pH}$ 6) or NPT ( $2 \mathrm{~g} / \mathrm{L}$ nutrient broth, $5 \mathrm{~g} / \mathrm{L}$ potato dextrose, $6 \mathrm{~g} / \mathrm{L}$ tryptic soy broth, $2 \mathrm{~g} / \mathrm{L}$ MES hydrate, $\mathrm{pH}$ 5.75), with or without $500 \mathrm{mg} / \mathrm{L}$ L-Tryptophan as the precursor for IAA biosynthesis. After $42 \mathrm{~h}$ incubation at $28{ }^{\circ} \mathrm{C}$ and $150 \mathrm{rpm}$, the culture was centrifuged at 5,500 $\mathrm{x} \mathrm{g}$ for $10 \mathrm{~min}$, and $1 \mathrm{~mL}$ of supernatant was mixed with $4 \mathrm{~mL}$ of Salkowski's reagent $\left(150 \mathrm{~mL}\right.$ concentrated $\mathrm{H}_{2} \mathrm{SO}_{4}$, $250 \mathrm{~mL}$ distilled $\mathrm{H}_{2} \mathrm{O}, 7.5 \mathrm{~mL} 0.5 \mathrm{M} \mathrm{FeCl}_{3} \cdot 6 \mathrm{H}_{2} \mathrm{O}$ ) by vortexing briefly. The mixture was incubated in the dark at room temperature for $20 \mathrm{~min}$ [54] and absorbance was measured at $535 \mathrm{~nm}$ using a SmartSpec Plus Spectrophotometer (Bio-Rad Laboratories Inc., Hercules, CA, USA). Equivalent mixtures with non-inoculated media served as blanks for the spectrophotometry readings. IAA concentrations were determined using a standard curve for each medium type (MGN and NPT, with or without $500 \mathrm{mg} /$ L L-Tryptophan) spiked with 0 to $400 \mu \mathrm{g} / \mathrm{mL}$ crystalline IAA (Sigma-Aldrich Corp.). Values presented were divided by 5 , as the culture was diluted $5 \mathrm{x}$ in Salkowski's reagent.

\section{Lignin, cellulose, and hemicellulose degradation assays} Isolated bacterial colonies were transferred to minimal media $\left(6 \mathrm{~g} / \mathrm{L} \mathrm{NaCl}, 1 \mathrm{~g} / \mathrm{L}\left(\mathrm{NH}_{4}\right)_{2} \mathrm{SO}_{4}, 0.5 \mathrm{~g} / \mathrm{L} \mathrm{KH}_{2} \mathrm{PO}_{4}\right.$, $0.5 \mathrm{~g} / \mathrm{L} \mathrm{K}_{2} \mathrm{HPO}_{4}, 0.1 \mathrm{~g} / \mathrm{L} \mathrm{MgSO}_{4}, 0.1 \mathrm{~g} / \mathrm{L} \mathrm{CaCl}_{2}, 2 \mathrm{~g} / \mathrm{L}$ MES, $15 \mathrm{~g} / \mathrm{L}$ agar, pH 5.75 using $\mathrm{NaOH}$ ) supplemented with $1 \mathrm{~g} / \mathrm{L}$ of either alkali lignin, colloidal microcrystalline cellulose, or birchwood xylan (all from Sigma-Aldrich Corp.) as sole carbon sources. Plates were incubated at $37{ }^{\circ} \mathrm{C}$ for 4 days, and bacteria were transferred to fresh plates in order to confirm the results.

Cellulose degradation was detected by transferring colonies to minimal medium containing $1 \% \mathrm{w} / \mathrm{v}$ 
carboxymethylcellulose and $0.1 \mathrm{w} / \mathrm{v}$ glucose. After $48 \mathrm{~h}$, the plate was flooded with $5 \mathrm{~mL}$ of $0.1 \% \mathrm{w} / \mathrm{v}$ Congo red (Ricca Chemical Co., Arlington, TX, USA) and stained for $15 \mathrm{~min}$ at room temperature. After removing the dye, the plate was washed twice with $5 \mathrm{~mL} 1 \mathrm{M} \mathrm{NaCl}$ for 15 min each, then air dried and photographed.

Ligninolytic enzyme production was detected by transferring colonies to minimal medium containing $25 \mathrm{mg} / \mathrm{L}$ methylene blue at $28^{\circ} \mathrm{C}$ for $72 \mathrm{~h}$.

\begin{abstract}
Abbreviations
ACC: 1-aminocyclopropane-1-carboxylate; IAA: indole-3-acetic acid; CFU: colony forming units; CR1: corn rhizobacterium 1; MES: 2-(N-morpholino)ethanesulfonic acid; MGN: medium containing mannitol, glutamate, nutrient broth, potato dextrose, tryptic soy, $\mathrm{KH}_{2} \mathrm{PO}_{4}, \mathrm{MgSO}_{4}, \mathrm{NaCl}$, biotin, and MES; MS: Murashige and Skoog medium; NBRIP: medium containing glucose, $\mathrm{Ca}_{3}\left(\mathrm{PO}_{4}\right)_{2}, \mathrm{MgCl}_{2}$ $\left(\mathrm{NH}_{4}\right)_{2} \mathrm{SO}_{4}, \mathrm{MgSO}_{4}$, and $\mathrm{KCl}$. Growth is associated with the capacity to use inorganic phosphate in the form of $\mathrm{Ca}_{3}\left(\mathrm{PO}_{4}\right)_{2}$ as a sole phosphate source; NFM: nitrogen-free minimal medium; NPT: medium containing nutrient broth, potato dextrose, tryptic soy, and MES; PDA: potato dextrose agar; PNCM: potato nodal cutting medium; WT: wild-type
\end{abstract}

\section{Acknowledgements}

We would like to thank Dane Nickel, Zach Hansen, Elliot Nicholas Grady, Ahmed Abd-Elmagid and Nathaniel Chow for discussions. This research was funded by the Agriculture and Agri-Food Canada Growing Forward-AgriFlex (RBPI number 2555), Agriculture and Agri-Food Canada Growing Forward II project 1670, as well as a Natural Sciences and Engineering Research Council of Canada (NSERC) Discovery Grant (RGPIN-2015-06052) awarded to Z-C Yuan

\section{Funding}

This research was funded by the Agriculture and Agri-Food Canada Growing Forward-AgriFlex (RBPI number 2555), Agriculture and Agri-Food Canada Growing Forward II project 1670, as well as a Natural Sciences and Engineering Research Council of Canada (NSERC) Discovery Grant (RGPIN-2015-06052) awarded to Z-C Yuan. The funding body was not involved in the design of the study; in the collection, analysis, and interpretation of data; or in writing the manuscript.

\section{Availability of data and material}

The dataset generated for phylogenetic tree construction is available in the TreeBASE repository, http://purl.org/phylo/treebase/phylows/study/TB2:S19845

\section{Authors' contributions}

BW, NN and AWE conducted the experiments and prepared the manuscript. $J M$ critically revised the manuscript and contributed to data analysis and interpretation. ZCY conceived of the study, isolated the bacterium and edited the manuscript. All authors read and approved the final manuscript.

\section{Competing interests}

The authors declare that they have no competing interests.

\section{Consent for publication}

Not applicable

\section{Ethics approval and consent to participate}

Not applicable

\author{
Author details \\ 'London Research and Development Centre, Agriculture \& Agri-Food \\ Canada, 1391 Sandford Street, London, ON N5V 4T3, Canada. ${ }^{2}$ Department of \\ Biology, Biological and Geological Sciences Building, University of Western \\ Ontario, London, ON N6A 5B7, Canada. ${ }^{3}$ Department of Microbiology \& \\ Immunology, Dental Science Building Rm. 3014, University of Western \\ Ontario, London, ON N6A 5C1, Canada.
}

Received: 22 June 2016 Accepted: 7 October 2016 Published online: 18 October 2016

\section{References}

1. Dobermann A. Nutrient use efficiency - measurement and management. In Krauss A, Association internationale de l'industrie des engrais, Isherwood K (Eds) Fertilizer Best Management Practice: General Principles, Strategy for their Adoption and Voluntary Initiatives vs Regulations. IFA International Workshop On Fertilizer Best Management Practices. Brussels, Belgium. 2007.

2. Sarathchandra SU, Ghani AA, Yeates GW, Burch G, Cox NR. Effect of nitrogen and phosphate fertilizers on microbial and nematode diversity in pasture soils. J Biol Biochem. 2001;33:953-64.

3. Arias-Estévez M, López-Periago E, Martínez-Carballo E, Simal-Gándara J, Mejuto JC, García-Río L. The mobility and degradation of pesticides in soils and the pollution of groundwater resources. Agr Ecosyst Environ. 2008;123:247-60.

4. Bloemberg GV, Lugtenberg BJJ. Molecular basis of plant growth promotion and biocontrol by Rhizobacteria. Curr Opin Plant Biol. 2001;4:343-50.

5. Bohlool BB, Ladka JK, Garrity DP, George T. Biological nitrogen fixation for sustainable agriculture : A perspective. Plant Soil. 1992;141:1-11.

6. Jakobsen J, Leggett ME, Richardson AE. Rhizosphere microorganisms and plant phosphorous uptake. In: Sims JT, Sharpley AN, editors. Phosphorous: agriculture and the environment. Madison, WI, USA.: American Society for Agronomy; 2005. p. 439-94.

7. Rodriguez H, Fraga R. Phosphate solubilizing bacteria and their role in plant growth promotion. Biotechnol Adv. 1999;17:319-39.

8. Glick B, Cheng Z, Czarny J, Duan J. Promotion of plant growth by ACC deaminase producing soil bacteria. Eur J Plant Pathol. 2007;119:329-39.

9. Glickmann E, Dessaux Y. A critical examination of the specificity of the Salkowski reagent for indolic compounds produced by phytopathogenic bacteria. Appl Env Microbiol. 1995;61:793-6.

10. Patten CL, Glick BR. Role of Pseudomonas putida indoleacetic acid in development of the host plant root system. Appl Env Microbiol. 2002;68:3795-801.

11. Spaepen S, Vanderleyden J, Remans R. Indole-3-acetic acid in microbial and microorganism-plant signaling. FEMS Microbiol Rev. 2007;31:425-48.

12. Bhattacharyya PN, Jha DK. Plant growth-promoting rhizobacteria (PGPR): emergence in agriculture. World J Mcrobiol Biotechnol. 2012;28:1327-50.

13. Lal S, Tabacchioni S. Ecology and biotechnological potential of Paenibacillus polymyxa: a minireview. Indian J Microbiol. 2009;49:2-10.

14. Udeigwe TK, Teboh JM, Eze PN, Stietiya MH, Kumar V, Hendrix J, Mascagni Jr HJ, Ying T, Kandakji T. Implications of leading crop production practices on environmental quality and human health. J Environ Manage. 2015;151:267-79.

15. Ling N, Xue C, Huang Q, Yang X, Xu Y, Shen Q. Development of a mode of application of bioorganic fertilizer for improving the biocontrol efficacy to Fusarium wilt. BioControl. 2010;55:673-83.

16. Ryu CM, Kim J, Choi O, Kim SH, Park CS. Improvement of biological control capacity of Paenibacillus polymyxa E681 by seed pelleting on sesame. Biol Control. 2006;39:282-9.

17. Anand R, Grayston S, Chanway C. N2-fixation and seedling growth promotion of lodgepole pine by endophytic Paenibacillus polymyxa. Microb Ecol. 2013;66:369-74.

18. Puri A, Padda KP, Chanway CP. Evidence of nitrogen fixation and growth promotion in canola (Brassica napus L.) by an endophytic diazotroph Paenibacillus polymyxa P2b-2R. Biol Fert Soils. 2016;52:119-25.

19. Xie J, Shi H, Du Z, Wang T, Liu X, Chen S. Comparative genomic and functional analysis reveal conservation of plant growth promoting traits in Paenibacillus polymyxa and its closely related species. Sci Rep. 2016;6:21329.

20. Eastman AW, Heinrichs DE, Yuan ZC. Comparative and genetic analysis of the four sequenced Paenibacillus polymyxa genomes reveals a diverse metabolism and conservation of genes relevant to plant-growth promotion and competitiveness. BMC Genomics. 2014;15:851.

21. Eastman AW, Weselowski B, Nathoo N, Yuan ZC. Complete genome sequence of Paenibacillus polymyxa CR1, a plant growth-promoting bacterium isolated from the corn rhizosphere exhibiting potential for biocontrol, biomass degradation, and biofuel production. Genome Announc. 2014;2:e01218-13.

22. Eastman AW, Yuan ZC. Development and validation of an rDNA operon based primer walking strategy applicable to de novo bacterial genome finishing. Front Microbiol. 2015;5:769.

23. Timmusk S, van West P, Gow NAR, Huffstutler RP. Paenibacillus polymyxa antagonizes oomycete plant pathogens Phytophthora palmivora and Pythium aphanidermatum. J Appl Microbiol. 2009;106:1473-81.

24. Kim SG, Khan Z, Jeon YH, Kim YH. Inhibitory effect of Paenibacillus polymyxa GBR-462 on Phytophthora capsici causing phytophthora blight in chili pepper. J Phytopathol. 2009;157:229-37. 
25. Kavitha S, Senthilkumar S, Gnanamanickam A, Inayathullah M, Jayakumar R. Isolation and partial characterization of antifungal protein from Bacillus polymyxa strain VLB16. Process Biochem. 2005:40:3236-43.

26. Chen X, Wang G, Xu M, Jin J, Liu X. Antifungal peptide produced by Paenibacillus polymyxa BRF-1 isolated from soybean rhizosphere. Afr J Microbiol Res. 2010;4:2692-8.

27. Hong CE, Kwon SY, Park JM. Biocontrol activity of Paenibacillus polymyxa AC-1 against Pseudomonas syringae and its interaction with Arabidopsis thaliana. Microbiol Res. 2016;185:13-21.

28. Pichard B, Larue JP, Thouvenot D. Gavaserin and saltavalin, new peptide antibiotics produced by Bacillus polymyxa. FEMS Microbiol Lett. 1995;133:215-8.

29. Lee SH, Cho YE, Park SH, Balaraju K, Park JW, Lee SW, Park K. An antibiotic fusaricidin: a cyclic depsipeptide from Paenibacillus polymyxa E681 induces systemic resistance against Phytophthora blight of red-pepper. Phytoparasitica. 2013:41:49-58.

30. Mehnaz S, Weselowski B, Lazarovits G. Isolation and identification of Gluconacetobacter azotocaptans from corn rhizosphere. Syst Appl Microbiol. 2006;29:496-501.

31. Galloway JN, Cowling EB. Reactive nitrogen and the world: 200 years of change. AMBIO. 2002;31:64-71.

32. Rodriguez H, Fraga R, Gonzalez T, Bashan Y. Genetics of phosphate solubilization and its potential applications for improving plant growthpromoting bacteria. Plant Soil. 2006:287:15-21.

33. Wakelin SA, Warren RA, Harvey PR, Ryder MH. Phosphate solubilization by Penicillium spp. closely associated with wheat roots. Biol Fertil Soils. 2004:40:36-43.

34. Yadav KS, Dadarwal KR. Phosphate solubilization and mobilization through soil microorganisms. In: Dadarwal KR, editor. Biotechnological Approaches in Soil Microorganisms for Sustainable Crop Production. Jodhpur, India.: Scientific Publishers; 1997. p. 293-308.

35. Bashan Y. Inoculants of plant growth-promoting bacteria for use in agriculture. Biotechnol Adv. 1998;16:729-70.

36. Hardoim PR, van Overbeek LS, Elsas JD. Properties of bacterial endophytes and their proposed role in plant growth. Trends Microbiol. 2008;16:463-71.

37. Kim YC, Leveau J, McSpadden Gardner BB, Pierson EA, Pierson LS, Ryu C. The multifactorial basis for plant health promotion by plant-associated bacteria. Appl Environ Microbiol. 2011;77:1548-55.

38. Kuklinsky-Sobral J, Araujo WL, Mendes R, Geraldi IO, Pizzirani-Kleiner AA, Azevedo JL. Isolation and characterization of soybean-associated bacteria and their potential for plant growth promotion. Environ Microbiol. 2004;6:1244-51.

39. Li L, Hou X, Tsuge T, Ding M, Aoyama T, Oka A, Gu H, Zhao Y, Qu LK. The possible action mechanisms of indole-3-acetic acid methyl ester in Arabidopsis. Plant Cell Rep. 2008;27:575-84

40. Magalhães DB, De Carvalho MEA, Bon E, Neto JSA, Kling SH. Colorimetric assay for lignin peroxidase activity determination using methylene blue as substrate. Biotechnol Tech. 1996;10:273-6.

41. Carder JH. Detection and quantitation of cellulase by Congo red staining of substrates in a cup-plate diffusion assay. Anal Biochem. 1986;153:75-9.

42. Bugg TDH, Ahmad M, Hardiman EM, Singh R. The emerging role for bacteria in lignin degradation and bio-product formation. Curr Opin Biotechnol. 2011;22:394-400.

43. Galkiewicz JP, Kellogg CA. Cross-kingdom amplification using bacterialspecific primers: complications for coral microbial ecology. Appl Enviro Microbiol. 2008;74:7828-31.

44. Thompson JD, Gibson TJ, Plewniak F, Jeanmougin F. The CLUSTAL_X Windows interface: Flexible strategies for multiple sequence alignment aided by quality analysis tools. Nucleic Acids Res. 1997;25:4876-82.

45. Saitou N, Nei M. The neighbor-joining method: A new method for reconstructing phylogenetic trees. Mol Biol Evol. 1987;4:406-25.

46. Kluge AG, Farris JS. Quantitative phyletics and the evolution of anurans. Syst Zool. 1969;18:1-32.

47. Tamura K, Dudley J, Nei M, Kumar S. MEGA4: Molecular Evolutionary Genetics Analysis (MEGA) software version 4.0. Mol Biol Evol. 2007;24:1596-9.

48. Kimura M. A simple method for estimating evolutionary rate of base substitutions through comparative studies of nucleotide sequences. J Mol Evol. 1980;16:111-20.

49. Swofford DL. Phylogenetic analysis using parisomy (*and other methods). Version 3. Sunderland: Sinauer Associates; 1998.

50. Abraham EP, Gardner AD, Chain E, Heatley NG, Fletcher CM, Jennings MA, Florey HW. Further observations on penicillin. The Lancet. 1941;238:177-89.
51. Doebereiner J. Isolation and identification of aerobic nitrogen fixing bacteria. In: Alef K, Nannipieri P, editors. Methods in applied soil microbiology and biochemistry. Cambridge, MA, USA.: Academic; 1994. p. 134-41.

52. Bashan $Y$, Holguin $G$, Lifshitz R. Isolation and characterization of plant growth-promoting rhizobacteria. In: Glick BR, Thompson JE, editors. Methods in plant molecular biology and biotechnology. BocaRaton, FL, USA.: CRC Press; 1993. p. 331-45.

53. Mehta S, Nautiyal CS. An efficient method for qualitative screening of phosphate-solubilizing bacteria. Curr Microbiol. 2001;43:51-6.

54. Gordon SA, Weber RP. Colorimetric estimates of indoleacteic acid. Plant Physiol. 1951;26:192-5.

\section{Submit your next manuscript to BioMed Central and we will help you at every step:}

- We accept pre-submission inquiries

- Our selector tool helps you to find the most relevant journal

- We provide round the clock customer support

- Convenient online submission

- Thorough peer review

- Inclusion in PubMed and all major indexing services

- Maximum visibility for your research

Submit your manuscript at www.biomedcentral.com/submit 